DOI: 10.12731/2218-7405-2018-7-63-75

УДК 159.9 (045)

\title{
ИССЛЕДОВАНИЕ ЛИЧНОСТНЫХ ХАРАКТЕРИСТИК СТУДЕНТОВ, АКТИВНО ПОЛЬЗУЮЩИХСЯ СОЦИАЛЬНЫМИ СЕТЯМИ
}

\author{
Белова Т.А., Кечина М.А.
}

Предмет исследования. Психологические характеристики студентов, активно пользующихся сочиильными сетями.

Тема работы. Исследование психологических характеристик студентов, активно пользующихся сочииальныли сетями.

Цель. Статья посвящена актуальной в условиях современной общественной реальности теме нехимических зависимостей. Предметом анализа выступают личностные характеристики студентов, активно пользуюшихся сочиальныли сетями. Авторы ставят цель раскрыть особенности личности студентов, предрасположенных к зависимостям от сетей, разработать психолого-педагогические рекомендации по снижению риска возникновения зависимости.

Метод или методология проведенной работы. Анализ психолого-педагогической литературы по проблеме зависимости, диагностика личностных факторов «риска», повыпающих предрасположенность к возникновению зависимости от социальных сетей.

Результаты. Полученные данные свидетельствуют о том, что у большинства студентов выявлена высокая и средняя активность личности в виртуальном общении. Авторы утверждают, что чаще виртуальному общению склонны студенты, характеризующиеся неуверенностью в себе, имеющие трудности в общении и самораскрытии. На основании проведенного исследования авторами разработаны психолого-педагогические рекомендации по профилактике факторов «риска» возникновения зависимости от социальных сетей. 
Область применения результатов. Результать проведенной работы могут быть востребованы в организациях выстего образования, в социальной и воспитательной работе со студентами вуза.

Выводы. Эмпирическое исследование показало, что у больиинства студентов, участвующих в эксперименте, выявлена высокая и средняя активность личности в виртуальном общении. Чаще виртуальному общению склонны студенты, имеющие такие особенности личности, как неуверенность в себе, трудности в общении и самораскрытии.

Ключевые слова: психологические характеристики; студенты; сочииальные сети.

\section{INVESTIGATION OF PERSONAL CHARACTERISTICS OF STUDENTS, ACTIVE USED BY SOCIAL NETWORKS}

\section{Belova T.A., Kechina M.A.}

Subject of research. Psychological characteristics of students actively using social networks.

Topic. Research of psychological characteristics of students actively using social networks.

Summary. The article presents an experimental study of the personal characteristics of students who often use social networks, also reveals the specifics of the formation of young people's dependence on social networks. The developed psychological and pedagogical recommendations for students in order to prevent Internet addiction are presented.

Purpose. The article is devoted to the topic of non-chemical dependencies relevant in the conditions of modern social reality. The subject of the analysis are the personal characteristics of students actively using social networks. The author aims to reveal the features of the personality of students prone to dependence on networks, to develop psychological and pedagogical recommendations to reduce the risk of addiction.

Methodology. Analysis of psychological and pedagogical sources on the problem of research, comparative analysis of identifying personal 
risk factors that increase the predisposition to the emergence of dependence on social networks.

Results. The data obtained show that the majority of students have high and average activity of personality in virtual communication. The authors argue that more often virtual communication is prone to students, characterized by self-doubt, having difficulties in communication and self-disclosure. On the basis of the study the authors developed psychological and pedagogical recommendations for the prevention of "risk" factors of dependence on social networks.

Practical implications. The results of this work can be in demand in higher education institutions, in social and educational work with students of the University.

Conclusions. The Empirical study showed that the majority of students participating in the experiment, revealed a high and average activity of the individual in virtual communication. More often, virtual communication tend to students with such personality traits as self-doubt, difficulties in communication and self-disclosure.

Keywords: psychological characteristics; students; social networks.

\section{Введение}

Современный человек, находясь в условиях быстро меняющейся реальности, преобразует свой образ жизни, личностное восприятие, смысложизненныеориентиры. С каждым днем скорость этих социально-экономических и общественных изменений существенно возрастает. Одним из значимых факторов, преобразующих личность, в настоящее время является ее активное общение в социальных сетях. Появление социальных сетей привело к расширению коммуникативного потенциала личности, существенно изменило характер общения и межличностного взаимодействия. Современный мир насыщен разнообразием оружия информационного характера, направленного на сознание и психику человека [2, с. 128].

Социальные сети - это «онлайн сервис, предназначенный для создания, организации и отражения всестороннего общения между реальными людьми в интернете» $[5$, с. 12$]$. Чрезмерное увлечение 
социальными сетями может негативно отразиться на психологическом благополучии личности, о чем пишут, как отечественные ученые (А.Е. Богомолова[1], А.Е. Войскунский [3], Н.П. Козлова [5], Д.Г. Рыбалтович [7], так и зарубежные Dolan C.A. [10], Diener E. [11], Ostvik K. [12], Lonnqvist J.E. [13], Ry C. [14], Chaldini R. [15].

Социальные сети привлекают молодых людей из-за возможности анонимного общения, можно не показывать, кем ты являешься на самом деле, особенно в случае присутствия у личности массы комплексов, которые возможно скрыть благодаря социальным сетям [4]. Наиболее распространенными сетями являются «Одноклассники», «В контакте», «Twitter», «Tambler», «Instagram». С каждым днем разработчики сетей трудятся над более новыми обновлениями, тем самым, привлекая все большее количество пользователей [6]. В ракурсе этой проблемы необходимо отметить, что в процессе «организации обучения студентов когнитивным способам саморегуляции и рациональным приемам управления эмоциональными состояниями осуществляется развитие социального мышления» [4, c. 22]. Ряд ученых видят решение данной проблемы посредством развития позитивного мышления, которое выполняет ряд функций в развитии личности: оздоровления, адаптации к новым условиям и формирования активной гражданской жизненной позиции [8]. Психологическая безопасность рассматривается как «защищенность личности, предполагающую наряду с внешними условиями безопасности, еще и внутренние» [4].

На основе выше сказанного, можно отметить, что в современных условиях социальные сети занимают существенную часть времени среди молодых людей. Профилактика зависимости от социальных сетей должна реализовываться посредством межведомственного взаимодействия различных государственных и общественных структур. Профилактика зависимости должна начинаться с раннего выявления психологических факторов возникновения зависимости, разработку и реализацию психоразвивающих и психопрофилактических программ, направленных на устранение негативного влияния на молодых людей различных социальных сетей. 


\section{Описание исследования}

Для исследования личностных характеристик студентов, активно пользующихся социальными сетями, мы использовали: опросник «Активность личности в виртуальной социальной сети» Е.И. Богомоловой [1, с. 94-96], направленный на выявление активности личности студентов в виртуальном общении, и опросник «Диагностика самоактуализации личности» [6, с. 192-196], направленный на изучение самоактуализации личности студентов как важнейшего психологического ресурса, препятствующего формированию зависимости.

Участниками исследования явились студенты физической культуры направления подготовки Педагогическое образования Профиль Физическая культура. Безопасность жизнедеятельности ФГБОУ ВО «Мордовский государственный педагогический институт им. М.Е. Евсевьева».

Результаты исследования личностных характеристик студентов, активно пользующихся социальными сетями, отражены в таблицах 1-2.

Таблицуа 1.

Показатели активности студентов в виртуальной социальной сети

\begin{tabular}{|l|c|c|}
\hline \multicolumn{1}{c|}{$\begin{array}{c}\text { Уровни } \\
\text { в виртувности студентов }\end{array}$} & $\begin{array}{c}\text { Показатели актив- } \\
\text { ности студентов } \\
\text { в виртуальном } \\
\text { общении }\end{array}$ \\
\cline { 2 - 3 } Высокая активность личности в виртуальном общении & 10 & 40 \\
\hline Средняя активность личности в виртуальном общении & 8 & 32 \\
\hline Низкая активность личности в виртуальном общении & 7 & 28 \\
\hline
\end{tabular}

Анализ полученных результатов, представленных в таблице 1, показывает, что у большинства испытуемых выявлена высокая и средняя активность личности в виртуальном общении.

Анализ полученных результатов показывает, что у 3 (16,7\%) испытуемых выявлен высокий уровень шкалы ориентации во времени, у 5 (27,8\%) испытуемых - средний уровень, у 10 (55,5\%) испытуемых - низкий уровень. 
Таблицуа 2.

Показатели самоактуализации студентов, часто пользующихся социальными сетями

\begin{tabular}{|c|c|c|c|c|c|c|}
\hline \multirow{3}{*}{$\begin{array}{c}\text { Шкалы } \\
\text { самоактуализации студентов }\end{array}$} & \multicolumn{6}{|c|}{$\begin{array}{c}\text { Показатели самоактуализации } \\
\text { студентов }\end{array}$} \\
\hline & \multicolumn{2}{|c|}{$\begin{array}{c}\text { Высокий } \\
\text { уровень }\end{array}$} & \multicolumn{2}{|c|}{$\begin{array}{c}\text { Средний } \\
\text { уровень }\end{array}$} & \multicolumn{2}{|c|}{$\begin{array}{r}\text { Низкий } \\
\text { уровень }\end{array}$} \\
\hline & Абс. & $\%$ & Абс. & $\%$ & Абс. & $\%$ \\
\hline Шкала ориентации во времени & 3 & 16,7 & 5 & 27,8 & 10 & 55,5 \\
\hline Шкала ценностей & 4 & 22,2 & 6 & 33,3 & 8 & 44,5 \\
\hline Взгляд на природу человека & 8 & 44,5 & 6 & 33,3 & 4 & 22,2 \\
\hline Высокая потребность в познании & 5 & 27,8 & 7 & 38,9 & 6 & 33,3 \\
\hline Стремление к творчеству или креативность & 8 & 44,5 & 6 & 33,3 & 4 & 22,2 \\
\hline Автономность & 4 & 22,2 & 6 & 33,3 & 8 & 44,5 \\
\hline Спонтанность & 8 & 44,5 & 6 & 33,3 & 4 & 22,2 \\
\hline Самопонимание & 5 & 27,8 & 6 & 33,3 & 7 & 38,9 \\
\hline Аутосимпатия & 5 & 27,8 & 7 & 38,9 & 6 & 33,3 \\
\hline Шкала контактности & 8 & 44,5 & 6 & 33,3 & 4 & 22,2 \\
\hline Шкала гибкости в общении & 4 & 22,2 & 6 & 33,3 & 8 & 44,5 \\
\hline
\end{tabular}

Как показывают исследования, высокий уровень шкалы ориентации во времени характерен для студентов, хорошо ориентирующихся во времени, ценящих свое время, предпочитаемых реальное общение виртуальному. Студенты, имеющие низкие показатели, отличаются погруженностью в себя, мнительностью и неуверенностью, комплексами в себе, предпочитающие виртуальное общение.

У 4 (22,2\%) испытуемых выявлен высокий уровень шкалы ценностей, у $6(33,3 \%)$ испытуемых - средний уровень, у 8 (44,5\%) испытуемых - низкий уровень. Студенты, имеющие высокие показатели, обладают такими ценностямисамоактуализирующейся личности, как: доброта, жизнелюбие, креативность, самодостаточность. Студенты, имеющие низкие показатели, отличаются стремлением к дисгармоничному бытию, нарушением установления позитивных межличностных отношений.

У 8 (44,5\%) испытуемых выявлен высокий уровень (положительный взгляд на природу человека), у 6 (33,3\%) испытуемых - средний уровень, у 4 (22,2\%) испытуемых - низкий уровень (отрицательный 
взгляд на природу человека). Студенты, обладающие высоким показателем по данной шкале, умеют выстроить гармоничные межличностные отношения. Испытуемые, обладающие низким показателем, имеют предпосылки для установления агрессивных неконструктивных межличностных отношений, предпочитают в большей степени общение в социальных сетях.

У 5 (27,8\%) испытуемых выявлена высокая потребность в познании, у 7 (38,9\%) испытуемых - средний уровень, у 6 (33,3\%) испытуемых - низкий уровень. Студенты, имеющие высокую потребность в познании, всегда открыты новым впечатлениям, знакомствам и общению в реальной жизни.

У 8 (44,5\%) испытуемых выявлен высокий уровень стремления к творчеству, у 6 (33,3\%) испытуемых - средний уровень, у 4 (22,2\%) испытуемых - низкий уровень. Студенты, имеющие высокие показатели стремления к творчеству, отличаются творческим отношением к жизни, предпочитают «живое» общение, занимаются активным социальным проектированием.

У 4 (22,2\%) испытуемых выявлен высокий уровень автономности, у 8 (44,5\%) испытуемых - средний уровень, у 6 (33,3\%) испытуемых - низкий уровень. Студенты, имеющие высокие показатели автономности, представляют собой как самоактуализирующиеся личности, прежде всего в реальном межличностном общении.

У 8 (44,5\%) испытуемых выявлен высокий уровень спонтанности, у 6 (33,3\%) испытуемых - средний уровень, у 4 (22,2\%) испытуемых - низкий уровень. Студенты, имеющие низкие показатели, обладают неуверенностью в себе, не доверяют к окружающему миру.

У 5 (27,8\%) испытуемых выявлен высокий уровень самопонимания, у 6 (33,3\%) испытуемых - средний уровень, у 7 (38,9\%) испытуемых - низкий уровень. Высокий показатель по этой шкале свидетельствует об осознанной рефлексии своих чувств, потребностей, мотивации. Низкий балл по шкале самопонимания свойственен студентам с заниженной самооценкой, неуверенных в собственных силах, возможностях. Такие студенты часто становятся объектом манипулирования в социальных сетях. 
У 5 (27,8\%) испытуемых выявлен высокий уровень аутосимпатии, у 6 (33,3\%) испытуемых выявлен средний уровень, у 7 (38,9\%) испытуемых низкий уровень. Студенты, имеющие низкие показатели, являются тревожными, неуверенными в себе. Студенты, имеющие высокие показатели, обладают осознаваемым позитивным «Я-образом».

У 8 (44,5\%) испытуемых выявлен высокий уровень контактности, у 6 (33,3\%) испытуемых - средний уровень, у 4 (22,2\%) испытуемых - низкий уровень. Студенты, имеющие высокие показатели, обладают общительностью, способностью к установлению прочных и доброжелательных отношений с окружающими.

У 4 (22,2\%) испытуемых выявлен высокий уровень гибкости в общении, у 6 (33,3\%) испытуемых - средний уровень, у 8 (44,5\%) испытуемых - низкий уровень. Студенты, имеющие высокие показатели, имеют положительный опыт взаимодействия с окружающими, способность к самораскрытию, ориентированы на самопознание. Низкие показатели характерны для студентов, не уверенных в себе.

Таким образом, у большинства испытуемых выявлена высокая и средняя активность личности в виртуальном общении. Чаще виртуальному общению склонны студенты, характеризующиеся неуверенностью в себе, имеющие трудности в общении и самораскрытии.

На основе проведенного исследования мы разработали следующие психолого-педагогические рекомендации:

1. Прежде чем зайти в любую социальную сеть, спросите себя, зачем Вы это делаете. Необходимо поставить перед собой конкретную задачу и не отвлекаться на другие.

2. Установите временной лимит на свое пребывание в социальных сетях. Обычно для того, чтобы ответить на вопросы, просмотреть фотографии и прочитать новости достаточно 20 минут.

3. Если Вы оправдываете свое «зависание» в Одноклассниках необходимостью снятия усталости, необходимо найти понастоящему эффективный способ релаксации, например, приобрести абонемент на занятия йогой либо в бассейн. 
4. Нужно помнить, что никакая социальная сеть не заменит живое общение. Введите традицию в определенный день недели встречаться с друзьями, при этом договоритесь на время встречи отключать свои мобильные телефоны и смартфоны.

5. От любой вредной привычки очень трудно избавиться. Для прекращения или уменьшения времени своего пребывания в виртуале, необходимо обратиться за помощью к специалисту.

\section{Заключение}

1. В настоящее время социальные сети занимают большую часть времени среди студентов.

2. Общение в социальных сетях - это один из значимых факторов, преобразующих личность студента.

3. Эмпирическое исследование показало, что у большинства студентов, участвующих в эксперименте, выявлена высокая и средняя активность личности в виртуальном общении.

4. Чаще виртуальному общению склонны студенты, имеющие такие особенности личности, как неуверенность в себе, трудности в общении и самораскрытии.

5. Профилактика от Интернет-зависимости должна реализовываться посредством взаимодействия различных государственных и общественных структур, реализовываться посредством формирования психологических ресурсов личности, препятствующие возникновению зависимости.

Информация о конфликте интересов. Исследование не имеет конфликта интересов.

Информация о спонсорстве. Исследование выполнено в рамках гранта на проведение научно-исследовательских работ по приоритетным направлениям научной деятельности вузов-партнеров по сетевому взаимодействию (Южно-Уральский государственный гуманитарно-педагогический университет и Мордовский государственный педагогический институт им. М.Е. Евсевьева) по теме «Психолого-педагогические условия профилактики зависимости студентов вуза от социальных сетей». 


\section{Список литературы}

1. Богомолова А.Е. Взаимосвязь личностных характеристик с особенностями активности пользователей социальных сетей Интернета: автореф. дис. ... канд. пед. науки: 19.00.01 / А. Е. Богомолова; Моск. город. пед.ун-т. М., 2015. 25 с.

2. Варданян Ю.В. Профессиональная психологическая подготовка как фактор психологической безопасности / Ю.В. Варданян, О.М. Воробьева // Вестник Челябинского государственного университета. 2017. № 7. С. 127-132.

3. Войскунский А.Е. Актуальные проблемы психологии зависимости от Интернета / А.Е. Войскунский // Психологический журнал, 2004. С. $90-100$.

4. Вдовина Н.А. Развитие социального мышления и профессионально-ценностных ориентаций бакалавров направления подготовки Педагогическое образование в процессе изучения курсов по выбору / Н.А. Вдовина, С.В. Сергунина // Гуманитарные науки и образование. 2014. № 1. С. 20-24.

5. Козлова Н.П. Негативное влияние социальных сетей на формирование личности / Н.П. Козлова, Э.Я. Гаджалиева // Современные тенденции развития науки и технологий. 2016. № 23. С. 33-36.

6. Лызь Н.А. Развитие безопасной личности в образовательном процессе вуза: монография. Таганрог: Изд-во ТРТУ, 2005. 305 с.

7. Рыбалтович Д.Г. Интернет-зависимость: реальная патология или норма развития информационного человечества? / Д.Г. Рыбалтович, В.В. Зайцев // Вестник психотерапии. 2011. № 40 (45). C. $25-44$.

8. Сергунина С.В. Особенности позитивного мышления студентов-волонтеров / С.В. Сергунина, А.А. Чалмаева // Гуманитарные науки и образование. 2017. № 11. С. 296-302.

9. Фетискин Н.П. Социально-психологическая диагностика развития личности и малых групп / Н.П. Фетискин, В.В. Козлов, Г.М. Мануйлов. М.: Изд-во Института Психотерапии, 2002. С. 45-90.

10.Dolan C.A., Ender M.G. The coping paradox: Work, stress, and coping in the U.S. Army // Military Psychology. 2008. V. 20(3), pp. 156-178. 
11. Diener E., Diener C. Most people are happy // Psychological Science. № 7. 1996, pp. 187-189.

12. Ostvik K., Rudmin F. Bullying and hazing among Norwegian army soldiers: Two studies of prevalence, context, and cognition // Military Psychology. 2001. V. 13(1), pp. 42-44.

13.Lonnqvist J.-E., Verkasalo M., Haukka J. et al. Premorbid personality factors in schizophrenia and bipolar disorder: Results from a large cohort study of male conscripts // Journ. of Abnormal Psychology. 2009. V. 118(2), pp. 419-427.

14. Ry C., Singer B. Know yself and Become What You Are: A Eudaimonic Approach to Psychological Well-Being // Journal of Happiness Studies. March 2008. № 9(1), pp. 52-67.

15. Чалдини Р. Психология влияния. Убеждай, воздействуй, защищайся. СПб.: Питер, 2010. 336 с.

\section{References}

1. Bogomolova A.E. Vzaimosvyaz'lichnostnykh kharakteristik s osobennostyami aktivnosti pol'zovateley sotsial'nykh setey Interneta [The relationship of personal characteristics with the peculiarities of the activity of users of social networks on the Internet]; Mosk. gorod. ped.un-t. M., 2015. 25 p.

2. Vardanyan Yu.V., Vorob'eva O. M. Vestnik Chelyabinskogo gosudarstvennogo universiteta. 2017. № 7. S. 127-132.

3. Voyskunskiy A.E. Psikhologicheskiy zhurnal, 2004, pp. 90-100.

4. Vdovina N.A., Sergunina S.V. Gumanitarnye nauki i obrazovanie. 2014. № 1, pp. 20-24.

5. Kozlova N.P., Gadzhalieva E.Ya. Sovremennye tendentsii razvitiya nauki i tekhnologiy. 2016. № 23, pp. 33-36.

6. Lyz' N.A. Razvitie bezopasnoy lichnosti v obrazovatel'nom protsesse vuza [The development of a safe personality in the educational process of the university]. Taganrog : Izd-vo TRTU, 2005. 305 p.

7. Rybaltovich D.G., Zaytsev V.V. Vestnik psikhoterapii. 2011. № 40 (45), pp. 25-44.

8. Sergunina S.V., Chalmaeva A.A. Gumanitarnye nauki i obrazovanie. 2017. № 11, pp. 296-302. 
9. Fetiskin N.P., Kozlov V.V., Manuylov G.M. Sotsial'no-psikhologicheskaya diagnostika razvitiya lichnosti i malykh grupp [Socio-psychological diagnosis of personal development and small groups]. M.: Izd-vo Instituta Psikhoterapii, 2002, pp. 45-90.

10. Dolan C.A., Ender M.G. The coping paradox: Work, stress, and coping in the U.S. Army. Military Psychology. 2008. V. 20(3), pp. 156-178.

11. Diener E., Diener C. Most people are happy. Psychological Science. № 7. 1996, pp. 187-189.

12. Ostvik K., Rudmin F. Bullying and hazing among Norwegian army sol-diers: Two studies of prevalence, context, and cognition. Military Psychology. 2001. V. 13(1), pp. 42-44.

13.Lonnqvist J.-E., Verkasalo M., Haukka J. et al. Premorbid personality factors in schizophrenia and bipolar disorder: Results from a large cohort study of male conscripts. Journ. of Abnormal Psychology. 2009. V. 118(2), pp. 419-427.

14. Ry C., Singer B. Know yself and Become What You Are: A Eudaimon-ic Approach to Psychological Well-Being. Journal of Happiness Studies. March 2008. № 9(1), pp. 52-67.

15. Cialdini R.B. Ubezhday, vozdeystvuy, zashchishchaysya [Influence. Science and Practice]. SPb.: Piter, 2010. 336 p.

\section{ДАННЫЕ ОБ АВТОРАХ}

Белова Татьяна Александровна, кандидат психологических наук. доцент кафедры психологии

Мордовский государственный педагогический институт имени М.Е. Евсевьева

ул. Студенческая, 11a, г. Саранск, Республика Мордовия, Российская Федераиия

tabelova79@yandex.ru

Кечина Марина Александровна, старший преподаватель кафедры психологии Мордовский государственный педагогчческий институт имени М.Е. Евсевьева 
ул. Студенческая, 11a, г. Саранск, Республика Мордовия, Российская Федерация

kechina22@rambler.ru

\section{DATA ABOUT THE AUTHORS}

Belova Tatyana Aleksandrovna, Candidate of Psychological Sciences, Docent of the Department of Psychology

Mordovian State Pedagogical Institute named after M.E. Evsevyev 11a, Studencheskaya Str., Republic of Mordovia, Saransk, 430007, Russian Federation

tabelova79@yandex.ru

SPIN-code: 2781-7987

ORCID: 0000-0002-0578-3476

Kechina Marina Aleksandrovna, Senior Lecturer, Department of Psychology

Mordovian State Pedagogical Institute named after M.E. Evsevyev 11a, Studencheskaya Str., Republic of Mordovia, Saransk, 430007, Russian Federation

kechina22@rambler.ru

SPIN-code: 2996-0468

ORCID: 0000-0002-5049-5932 